\title{
30ª REUNIÃO ANUAL - ANO 30 DA SOCIEDADE BRASILEIRA DE QUÍMICA
}

Para que uma reunião anual da Sociedade Brasileira de Química (RASBQ) seja adequadamente preparada e conduzida, o planejamento bem antecipado é fundamental. Neste ano, especificamente, todos desejavam realizar uma RASBQ que marcasse os 30 anos da Sociedade de forma especial. O desejo de realizar uma comemoração diferenciada foi assunto de várias reuniões da Diretoria e Conselho Consultivo e os preparativos tiveram início mesmo antes da realização da 29a. Assim em janeiro de 2006 começaram as conversações com o então Presidente da Royal Society of Chemistry, Dr. Simon Campbell, para uma possível atividade conjunta SBQ RSC. Ao mesmo tempo, o Presidente Paulo Cezar Vieira agia como nosso representante junto à American Chemical Society na preparação de atividade conjunta SBQ - ACS. Para comemorar a grandeza da SBQ, planejava-se fazer uma RASBQ com especial inserção internacional. Em julho/agosto de 2006, juntamente com o Prof. Fritz Frimmel (Universidade de Karlsruhe, Alemanha) reunimonos com o presidente da Gesellschaft Deutscher Chemiker (Sociedade Alemã de Química) Prof. Dieter Jahn. Ambos asseguraram a participação de um representante alemão na $30^{\mathrm{a}} \mathrm{RASBQ}$.

Na mesma ocasião visitamos a Friederich-Alexander University Erlangen-Nuremberg, onde acertamos com o Reitor, Prof. KarlDieter Grüske, a vinda de uma delegação ao Brasil, por ocasião da $30^{a}$ RASBQ, para a entrega do diploma de doutor em química obtido pelo Dr. Blumenau naquela universidade, em 1846, quatro anos antes dele fundar a hoje cidade de Blumenau, em Santa Catarina. Por razões de disponibilidade de datas da comitiva alemã, a solenidade foi realizada em Blumenau, em 13 de abril de 2007, com as presenças do Prof. Grüske, do Ministro da Pesquisa, Ciência e Artes da Baviera, Dr. Thomas Goppel e do Presidente da SBQ. O Ministro Goppel entregou o referido diploma ao Prefeito em exercício da cidade de Blumenau. O Prof. Grüske declarou que o evento era conseqüência do trabalho de pesquisa realizado por iniciativa da $\mathrm{SBQ}^{1}$.

Para a programação conjunta SBQ - RSC acertaram-se detalhes em Havana, durante a realização do XXIII Congresso Latino Americano de Química, ao qual compareceram delegações de sociedades ligadas à FLAQ e também da RSC e da ACS. Em Londres, iniciaram-se negociações para a inclusão no Portal da CAPES das publicações da RSC, que culminaram com a aprovação pelo Prof. Jorge Guimarães, Presidente da CAPES, em comemoração aos 30 anos da SBQ. Tal fato foi divulgado por ele durante a cerimônia de abertura da Reunião, quando foi homenageado com uma placa comemorativa dos 30 anos da SBQ. Para estas negociações foram fundamentais as participações da Profa. Elenara Chaves Edler de Almeida, Coordenadora de Acesso à Informação Científica e Tecnológica da Diretoria de Programas da CAPES, e da
Dra. Alejandra Palermo, assessora da RSC. A todos com os quais se negociou, na CAPES e na RSC, a SBQ agradece uma vez mais.

Durante a $30^{\mathrm{a}}$ RASBQ verificou-se, como característica, o alto nível dos eventos realizados, como conferência de abertura, workshops, sessões de painéis, sessões coordenadas, lançamentos de livros, conferências plenárias, conferências de empresas, mini-cursos e simpósios.

Ao Presidential Symposium on US/Brazil Research Collaboration: Biomass Conversion to Biofuels, Biomaterials, and Chemicals compareceram o Dr. Gale Buchanan, Undersecretary of Agriculture, USDA e o Dr. Pedro Arraes, representante da EMBRAPA

À cerimônia de abertura da 30a RASBQ compareceu, também, o Cônsul Geral do Reino Unido, em São Paulo, Dr. Martin Raven, acompanhado de outros membros da representação diplomática, ao qual agradecemos pelo patrocínio do I RSC/SBQ Workshop Chemistry and Innovation, from spin-out to market, UK-Brazil Year of Science and Innovation.

A imprensa especializada deu ampla divulgação às atividades realizadas ${ }^{2-7}$.

As comissões organizadora e científica, coordenadas pelo Prof. Norberto Peporine Lopes, Secretário Geral da SBQ, foram incansáveis e realizaram trabalho perfeito na montagem da $30^{\text {a }}$ RASBQ. Mais uma vez foi marcante também o trabalho da Diretora Executiva da SBQ, Dirce Campos, e seus colaboradores, que envidaram todos os esforços no sentido de fazer a organização funcionar de forma perfeita e de proporcionar o maior conforto possível aos participantes. Os diretores das Divisões Científicas e das Secretarias Regionais colaboraram com entusiasmo para o brilhantismo da $30^{\mathrm{a}}$ RASBQ. Membros da Diretoria e do Conselho Consultivo fizeram o que foi possível para proporcionar dias de convivência produtiva e agradável. A todos a SBQ será sempre muito grata.

Antonio Sálvio Mangrich Presidente da $S B Q$

\section{REFERÊNCIAS}

1. Mangrich, A. S.; Quim. Nova 1991, 14, 68.

2. Começa a Reunião Anual da SBQ; http://www.agencia.fapesp.br/ boletim dentro.php?id=7238.

3. Zucco, C.; Formação básica, http://www.agencia.fapesp.br/ boletim dentro.php?id $=7242$

4. Barreiro,E.; Construção da Inovação; http://www.agencia.fapesp.br/ boletim_dentro.php?id=7249

5. Mangrich, A. S.; Mercado em expansão, http://www.agencia.fapesp.br/ boletim_dentro.php?id=7251

6. Ritter, S.; Chem. Eng. News 2007, 85 (23), 9.

7. Ritter, S. K.; Chem. Eng. News 2007, 85 (26), 15. 